\title{
Phlegm production and lung function among cigarette smokers changing tar groups during the 1970s
}

\author{
HEDLEY PEACH, ${ }^{1}$ D M HAYWARD, ${ }^{1}$ D $R$ ELLARD, ${ }^{2}$ R W MORRIS, ${ }^{1 *}$ AND \\ D SHAH ${ }^{1}$ \\ From the Department of Community Medicine, ${ }^{1}$ United Medical and Dental Schools of Guy's and St Thomas \\ Hospitals, St Thomas' Campus, London SE1; and National Institute for Medical Research, ${ }^{2}$ Mill Hill, London.
}

SUMMARY In 1971-3 data on smoking habits, cigarette brand smoked, morning phlegm production, and lung function were recorded for factory workers as part of the Heart Disease Prevention Project. These men were reassessed in 1984 and those who had always smoked cigarettes from the same tar group were compared with those who had dropped one tar group (mean decreases of $6.6 \mathrm{mg}$ tar, 0.1 mg nicotine) and two tar groups (mean decreases of $11.9 \mathrm{mg}$ tar, $0.5 \mathrm{mg}$ nicotine). Over the 13 years, men who had dropped one tar group were significantly more likely $(p<0.05)$ to stop producing phlegm, but the effect was less marked for those who had dropped two tar groups. The mean fall in $\mathrm{FEV}_{1}$ was similar in all three groups, but $95 \%$ confidence limits showed that although dropping one tar group could be associated with at most a saving of $84 \mathrm{ml}$ over the follow up period, there could be little extra benefit from dropping two tar groups. In 1984, all three groups of smokers excreted similar amounts of nicotine metabolites in the urine, suggesting that men who had dropped two tar groups $\stackrel{\mathbb{\Omega}}{\triangle}$ compensated for the reduced nicotine yield of their cigarettes. This could account for the lack of ao dose response relationship between reduction in the tar yield of cigarettes and cessation of phlegm and fall in $\mathrm{FEV}_{1}$.

The importance of cigarette smoking in the aetiology of chronic obstructive lung disease is well documented, and generally the severity of disease increases with increasing cigarette consumption. ${ }^{1}$ Because of this dose-response relationship, it was hoped that the smoking of cigarettes in a lower tar group would be less deleterious to the lungs.

Several studies have suggested that there might be a direct relationship between reduction in the tar yield of cigarettes and a reduced prevalence of $\operatorname{cough}^{2-6}$ and phlegm production..$^{2-9}$ Fewer studies have examined the potential importance of tar yield on change in pulmonary function. One prospective study ${ }^{2}$ found that smokers of plain cigarettes, compared to those smoking filter-tipped cigarettes, had a lower forced expiratory volume in one second $\left(\mathrm{FEV}_{1}\right)$ at entry into the study but a smaller reduction of $F E_{1}$ after five years. However, in another longitudinal survey multiple regression analysis did not show any significant association between tar yield and lung function. ${ }^{10}$ Cross-sectional surveys also indicate no relationship between pulmonary function and the use

*Address correspondence to: Mr R W Morris, Department of Community Medicine, United Medical and Dental Schools, St Thomas' Campus, London SEl 7EH. of filter-tipped versus plain cigarettes ${ }^{11}$ or cigarette tar yield. ${ }^{-}$

It has been suggested that mucus hypersecretion and chronic airflow obstruction are essentially distinct lung diseases, ${ }^{412}$ and it is possible that they might differ in their susceptibility to tar intakes. However, it would be premature to conclude that tar intake might not be an important factor in chronic airflow obstruction. Firstly, cross-sectional studies cannot define the natural history of a disease.

Secondly, Fletcher et $a t^{4}$ suggested that approximately eight years are necessary to establish rates of change of $\mathrm{FEV}_{1}$ with sufficient confidence even to distinguish between smokers and ex-smokers. Thirdly, there is usually no information on the lung function of smokers at the time they change from high to low tar cigarettes. It is possible that similar function differences may exist in subjects who choose between high and low tar cigarettes as have been observed in adults choosing to smoke or not. ${ }^{13}$

Government tables of the tar yields of cigarettes advise committed smokers to choose a cigarette in a lower tar group. In a recent survey, ${ }^{14}$ one-fifth of smokers recalled having changed from one tar group 
to another (usually downwards), the majority during the mid 1970s. Before this, in 1971-3, data on smoking habits including cigarette brand smoked, phlegm production, and $\mathrm{FEV}_{1}$ were recorded on factory workers as part of the Heart Disease Prevention Project. ${ }^{15}$ Assessment of their 1984 smoking habits, phlegm production, and $\mathrm{FEV}_{1}$ therefore enabled us to compare cigarette smokers who had and who had not changed tar groups for change in phlegm production and fall in $F E V_{1}$ over the past 13 years.

\section{Methods}

The UK Heart Disease Prevention Project (HDPP) was a randomised controlled trial of the potential benefits of advising middle-aged men in industry about reducing the level of coronary risk factors and taking treatment for hypzrtension. ${ }^{15}$ Twenty-four large industrial groups (mainly factories) were recruited between 1971 and 1973 and were then paired according to type of industry and area. One of each pair was randomly selected for the intervention programme while the other served as a control. The factories represented a cross-section of light, medium, and heavy industry. Within each factory the project included all men aged 40 to 59 regardless of their actual jobs, except in the South Wales steel workers where only office staff were included. The total number of subjects was 18210 (9734 intervention, 8476 control).

At the start of the HDPP all subjects in the intervention factories and $10 \%$ of the control group (10 $582 \mathrm{men}$ ) were offered a screening examination. Eighty six per cent (9101) of the men accepted. Their lung function was measured and data were collected about smoking habits, including brand of cigarette smoked, and morning phlegm production using standard questions.

A similar questionnaire about smoking habits and morning phlegm production in 1984 was mailed to all men (5661) who were contactable in the final HDPP follow-up in 1978. The questionnaire was accompanied by a letter asking the men whether they still worked at the same factory as they did at the start of the HDPP or lived within easy access of it. Cigarette smokers at the start of the HDPP who still smoked in 1984 and replied in the affirmative were invited to have a lung function test at the factories. Forced vital capacity manoeuvres were performed in the sitting position without noseclip using a vitalograph and function analyser. A tracing was considered acceptable if it was of six seconds' duration and if a maximal effort had been made. Three acceptable tracings on each subject were obtained, and the best effort was used to calculate the volume of air expired in

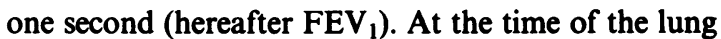
function test, the number of cigarettes smoked so far that day or the previous day was noted, and a sample of urine was collected. The urine samples were preserved with thymol and stored at room temperature before analysis at Mill Hill within about a week. The concentrations of nicotine metabolites and creatinine were measured using barbituric acid and alkaline picrate, respectively, and urinary nicotine metabolites/creatinine ratios were calculated. ${ }^{16} 17$

The tar and nicotine yields of the manufactured cigarettes smoked in 1984 and at the start of the HDPP were obtained from tables supplied by the laboratory of the Government Chemist. Tar groupings as defined in 1984 ("low" $\leqslant 10$, "low-middle" 11-16, "middle" $17-22$, "middle-high" $\geqslant 23 \mathrm{mg} / \mathrm{cig}$ ) wereused toidentify smokers of manufactured cigarettes who had always smoked cigarettes in the same tar group, those who had dropped one tar group and those who had dropped two or more tar groups since the start of the HDPP. These three types of smokers were compared for age, social class, smoking habits, morning phlegm

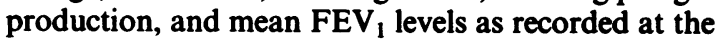
start of the HDPP. The independent effects on change in morning phlegm production or mean $\mathrm{FEV}_{1}$ levels were assessed using multiple regression models into which the following independent variables were entered: age, social class, height, baseline FEV level, $^{2}$ initial number of cigarettes smoked and inhalation, change in number of cigarettes smoked and inhalation, and change in tar group. It was thus possible to assess the effect of the change in tar group allowing for the effects of the other variables.

\section{Results}

\section{RESPONSE}

After a postcard reminder and a second mailing of the questionnaire, replies were received from 4182 of the 5661 men who had participated in the last HDPP follow-up in 1978. Of these, 1083 were smoking cigarettes and had done so since the start of the HDPP; 942 had a brand recorded both in 1984 and 13 years previously. Eight hundred and ten smokers still worked at the same factory as they did in 1971-3 or lived within travelling distance of it. After one reminder, 578 of these men attended the factories for a pulmonary function test. The mean $F E V_{1}$ at the start of the HDPP was slightly lower for the men who could not attend for a lung function test (3.0 litres) than for those on whom a lung function test was performed $(3 \cdot 1)$. Non-respondents were also slightly older (48.3 years) than respondents (47.7) and smoked more cigarettes per day (16.9 compared with $15 \cdot 3$ ). 
CHANGE IN TAR GROUPS 1971-84

One hundred and forty five men had always smoked a manufactured cigarette in the same tar group, mainly "middle tar", since the start of the HDPP. Three hundred and twenty two men had dropped one tar group, mainly from "middle-high" to "middle" or from "middle" to "low-middle", and 132 men had dropped two or more tar groups, mainly from "middle" to "low" or from "middle-high" to "low-middle". Five men who had increased the tar group of their cigarettes were excluded from the analyses. Three hundred and thirty eight men who had smoked hand rolled cigarettes at or since the start of the HDPP were also excluded.

\section{CHARACTERISTICS OF SMOKERS AT THE START OF THE HDPP}

Table 1 shows the age, social class, smoking habits, morning phlegm production, and mean $\mathrm{FEV}_{1}$ level of men at the start of the HDPP. Smokers who subsequently changed to a lower tar group smoked more heavily and smoked cigarettes with higher tar and nicotine yields in 1971. There was a trend for the prevalence of morning phlegm at the start of the study to increase from smokers who kept to cigarettes in the same tar group through to those who subsequently dropped two or more tar groups, although this trend was not statistically significant.

CHANGE IN TAR AND NICOTINE YIELDS OF CIGARETTES SMOKED 1971-84

The tar yield of the cigarettes smoked by men who kept to cigarettes in the same tar group during that time dropped by an average of $2.48 \mathrm{mg} /$ cigarette (table 2). A drop of one and two or more tar groups was associated with a reduction in tar yield of 6.55 and $11.92 \mathrm{mg} / \mathrm{cig}$ respectively. The mean nicotine yields of the cigarettes smoked by those who kept to the same tar group actually increased slightly, and the only

Table 1 Characteristics of cigarette smokers at the start of the HDPP

\begin{tabular}{|c|c|c|c|}
\hline \multirow[b]{2}{*}{ Variable } & \multicolumn{3}{|c|}{ Type of cigarette smoked 1971-84 } \\
\hline & $\begin{array}{l}\text { Same tar } \\
\text { group }\end{array}$ & $\begin{array}{l}\text { Dropped one } \\
\text { tar group }\end{array}$ & $\begin{array}{l}\text { Dropped two } \\
\text { tar groups }\end{array}$ \\
\hline \multirow{3}{*}{$\begin{array}{l}\text { Age } \\
\text { Social class } \\
\text { I-III NM (\%) } \\
\text { IIIM-V (\%) } \\
\text { Cigs/day } \\
\text { Tar yield (mg/cig) } \\
\text { Nicotine yield (mg/cig) } \\
\text { Inhale (\%) } \\
\text { Morning } \\
\text { phlegm (\%) } \\
\text { FEV l (litres) }\end{array}$} & $47.5(0.44)^{*}$ & $48.0 \quad(0.27)$ & $48.3 \quad(0.47)$ \\
\hline & $\begin{array}{l}28.2 \\
71.7 \\
17.4(0.73) \\
19.7(0.20) \\
1.28(0.02) \\
87\end{array}$ & $\begin{array}{cc}21.8 & \\
78.3 & \\
17.7 & (0.56) \\
22.5 & (0.23) \\
1.44 & (0.02) \\
86 & \end{array}$ & $\begin{array}{cc}27.3 & \\
72.8 & \\
18.5 & (0.79) \\
23.0 & (0.39) \\
1.47 & (0.03) \\
94 & \end{array}$ \\
\hline & $\stackrel{28}{3.1} \quad(0.05)$ & 32 & $\begin{array}{ll}37 \\
3.1 & (0.05)\end{array}$ \\
\hline${ }^{\mathbf{N}}$ mean (SE) & 145 & 322 & 132 \\
\hline
\end{tabular}

substantial decreases in nicotine yields were among those who changed down two or more tar levels.

It was only this last group who needed to compensate for the reduced nicotine yields of their cigarettes by smoking more heavily or taking deeper puffs. Assessment of phlegm production and $F E V_{1}$ in 1984 therefore enabled us to compare cigarette smokers who had experienced a large drop in the nicotine (as well as the tar) yield of their cigarettes and who needed to compensate, with smokers who dropped only the tar yield of their cigarette and also with smokers who did not change tar groups at all.

If compensation did not occur and there was a direct relationship between reduction in tar yield and reduction of respiratory symptoms and loss of $\mathrm{FEV}_{1}$, then a dose-response relationship in the form of consistent trends from men keeping to a cigarette of the same tar level, through men dropping one tar group (mean decreases of $6.6 \mathrm{mg}$ tar), to men dropping two tar levels (mean decreases of $11.9 \mathrm{mg}$ tar) might be expected in smaller mean drops in $\mathrm{FEV}_{1}$ and reduced prevalence of morning phlegm production.

\section{CHANGE IN PHLEGM PRODUCTION 1971-84}

Table 2 shows the change in morning phlegm production of the men between 1971 and 1984. Among those who had morning phlegm at the start of the HDPP, a greater proportion stopped bringing up

Table 2 Change in phlegm production, pulmonary function, and smoking habits of cigarette smokers between 1971 and 1984

\begin{tabular}{|c|c|c|c|}
\hline \multirow[b]{2}{*}{ Variable } & \multicolumn{3}{|c|}{ Type of cigarette smoked 1971-84 } \\
\hline & $\begin{array}{l}\text { Same tar } \\
\text { group }\end{array}$ & $\begin{array}{l}\text { Dropped one } \\
\text { tar group }\end{array}$ & $\begin{array}{l}\text { Dropped two } \\
\text { tar groups }\end{array}$ \\
\hline $\begin{array}{l}\text { Drop in tar yield } \\
\text { (mg/cig) } \\
\text { Change in nicotine } \\
\text { yield (mg/cig) }\end{array}$ & $\begin{array}{l}2.48(0.13)^{*} \\
0.14(0.02)\end{array}$ & $\begin{array}{r}6.55(0.17) \\
-0.10(0.01)\end{array}$ & $\begin{array}{r}11.92(0.24) \\
-0.47(0.02)\end{array}$ \\
\hline $\begin{array}{l}\text { Phlegm production } \\
\text { Developed morning } \\
\text { phlegm \% (N) } \\
\text { Stopped producing } \\
\text { morning phlegm \% (N) }\end{array}$ & $\begin{array}{l}17 \quad(103) \\
24 \quad(41)\end{array}$ & $\begin{array}{ll}21 & (214) \\
46 & (103)\end{array}$ & $\begin{array}{ll}28 & (82) \\
38 & (47)\end{array}$ \\
\hline $\begin{array}{l}\text { Lung function } \\
\text { Fall in FEV } 1 \\
\text { (litres) }\end{array}$ & $0.66(0.04)$ & $0.64(0.02)$ & $0.66(0.04)$ \\
\hline $\begin{array}{l}\text { Smoking habits } \\
\text { Change in cigs/day } \\
\text { Started inhaling \% (N) } \\
\text { Stopped inhaling \% (N) }\end{array}$ & $\begin{array}{cl}-1 \cdot 3 & (0.6) \\
50 & (17) \\
3 & (116)\end{array}$ & $\begin{array}{cl}-0.9 & (0.4) \\
54 & (41) \\
2 & (242)\end{array}$ & $\begin{array}{cl}-0.5 & (0.7) \\
86 & (7) \\
0 & (105)\end{array}$ \\
\hline $\begin{array}{l}\text { Urinary nicotine in } 1984 \\
\text { Cigs before urine test }\end{array}$ & $\begin{array}{ll}10.6 & (0.7) \\
15.6 & (1.7)\end{array}$ & $\begin{array}{ll}11.4 & (0.5) \\
17.3 & (1.2)\end{array}$ & $\begin{array}{ll}10.8 & (0.7) \\
18 \cdot 1 & (2 \cdot 1)\end{array}$ \\
\hline $\begin{array}{l}\mathbf{N} \\
\mathbf{N} \text { lung function tests }\end{array}$ & $\begin{array}{r}145 \\
90\end{array}$ & $\begin{array}{l}322 \\
199\end{array}$ & $\begin{array}{r}132 \\
76\end{array}$ \\
\hline
\end{tabular}


phlegm among smokers dropping one tar group than among those who kept to cigarettes in the same tar category $(p<0.05)$. However, fewer men stopped producing morning phlegm among those who dropped two or more tar groups (38\%) than among those who dropped only one tar category $(46 \%)$. Ninety five per cent confidence limits for the difference in two proportions suggested that dropping two tar groups was associated with at the most only an extra $\mathbf{9 \%}$ of smokers ceasing morning phlegm production compared with dropping one tar group despite twice the drop in tar yield.

Paradoxically, there was a non-significant trend among men who did not have phlegm at the start of the HDPP for the development of phlegm to increase from smokers who always kept to cigarettes in the same tar category through to those who subsequently dropped two or more tar groups. Although the two opposite trends were not themselves statistically significant, they did constitute a significant interaction between initial phlegm production and change in tar group $(p<0.05)$ so that subjects who initially produced phlegm, and those who initially did not, are considered separately in further analysis of phlegm production.

\section{CHANGE IN LUNG FUNCTION 1971-84}

Table 2 shows the change in mean $\mathrm{FEV}_{1}$ levels of the men between 1971 and 1984. The FEV 1 levels of the men who dropped one tar group fell by an average of $20 \mathrm{ml}$ less than did the $\mathrm{FEV}_{1}$ of smokers who kept to cigarettes in the same tar category. However, the fall in FEV 1 among those who dropped two or more tar groups was similar to that of smokers who kept to cigarettes in the same tar category. Ninety five percent confidence limits for the difference in two means suggested that dropping either one or two tar levels could have been associated with up to a $100 \mathrm{ml}$ (data from table 2) smaller fall in $\mathrm{FEV}_{1}$ compared with non-changers. Although we cannot firmly dismiss the possibility of a small beneficial trend of saving $F E V_{1}$ by dropping tar levels, it appears that this could be no more than 7-8 $\mathrm{ml}$ per annum for dropping two tar levels.

\section{PHLEGM MODEL}

A logistic model was fitted to data on morning phlegm production in 1984 consisting of all the explanatory variables including a change (if any) in the tar group of the cigarette smoked between 1971 and 1984 (table 3). Among smokers who had morning phlegm in 1971, those who dropped one tar group were still significantly less likely to continue to produce morning phlegm over the 13 years than men who kept to a cigarette in the same tar group (odds ratio 0.26 , $\mathrm{p}<0.01$ ) after taking other variables into account. Ninety five per cent confidence limits show that the
Table 3 Independent odds ratios of explanatory variables for having morning phlegm in 1984

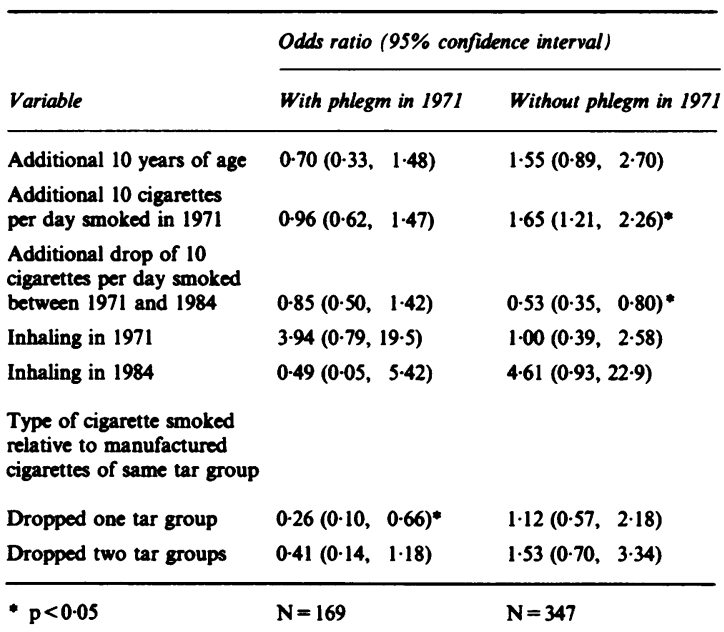

smallest odds ratio for having morning phlegm among men dropping two tar levels, $0 \cdot 14$, was similar to that of those dropping one tar level, $0 \cdot 10$, when compared with non-changers. There was still no evidence of a dose-response relationship between tar yield and stopping phlegm production.

Among smokers without phlegm in 1971, the proportion who subsequently developed phlegm increased with number of cigarettes smoked at the start of the HDPP and decreased with a reduction in the number smoked between 1971 and 1984 . Development of phlegm was still more likely among smokers dropping one and two or more tar groups than among men who kept to a cigarette in the same tar category (odds ratios 1.12 and 1.53 respectively) when other variables were taken into account.

\section{LUNG FUNCTION MODEL}

A linear model was fitted to the fall in $\mathrm{FEV}_{1}$ consisting of all the explanatory variables including a change (if any) in the tar group of the cigarette smoked between 1971 and 1984. The results are shown in table 4. Number of cigarettes smoked and level of FEV 1 in 1971 were positively and significantly related to the subsequent fall in $F E V_{1}$. After adjusting for all the other variables, there was no evidence that the small reduction in the number of cigarettes smoked between 1971 and 1984, shown in table 2, had an effect on the fall in $F_{E V}$. The falls in $F E V_{1}$ for men who reduced the tar yield of their cigarettes by one and two tar groups was now similar to that of the men who always smoked cigarettes in the same tar category when other variables were taken account of. Ninety five per cent confidence limits now suggested that dropping one tar group could have been associated with at the most an 
$84 \mathrm{ml}$ smaller fall in $\mathrm{FEV}_{1}$ compared with non-changers but that dropping two tar groups could be associated with at the most a $98 \mathrm{ml}$ smaller fall in $\mathrm{FEV}_{1}$. Hence the maximum possible saving by dropping two tar levels was still less than $8 \mathrm{ml}$ per annum after adjustment for other variables.

CHANGE IN SMOKING HABITS 1971-84

Table 2 also shows the change in smoking habits of the men between 1971 and 1984. All three types of smokers reduced the number of cigarettes smoked but men who always smoked cigarettes in the same tar group reduced more than did those who subsequently dropped one and two or more tar groups. The urinary excretion of nicotine metabolites was similar for all three types of smokers in 1984, suggesting that the men who dropped two tar groups compensated for the reduced nicotine yield of their cigarettes. Ninety five per cent confidence limits for the difference in two means suggested that the excretion of nicotine metabolites by the group who changed down two tar levels was at the most only $16 \%$ below that of the group of smokers who did not change down. Assuming that the inhalation of tar and excretion of nicotine metabolites are correlated (see discussion), then the group who changed down two tar levels reduced their tar intake by $3 \mathrm{mg} / \mathrm{cig}$ at the most. A reduction of this magnitude is of little clinical significance, and compensation was apparently more or less complete.

\section{Discussion}

One of the difficulties in interpreting cross-sectional studies of the relationship between cigarette tar yield

Table 4 Independent additive effects of various explanatory variables on fall in FEV $V_{l}$ between 1971 and 1984

\begin{tabular}{lc}
\hline Variable & Mean fall in FEVI (SE) (litres) \\
\hline $\begin{array}{l}\text { Additional } 10 \text { years of age } \\
\text { Additional } 10 \text { cigarettes per }\end{array}$ & $0.064(0.037)$ \\
day smoked in 1971 & $0.069(0.021)^{*}$ \\
Additional drop of 10 cigarettes & \\
per day between 1971 and 1984 & $-0.021(0.027)$ \\
Inhaling in 1971 & $0.047(0.058)$ \\
Inhaling in 1984 & $-0.076(0.082)$ \\
Manual social class (IIIM-V) & $-0.059(0.039)$ \\
Additional 10\% in level of & \\
FEV 1 in 1971 & $-0.649(2.926)$ \\
Type of cigarette smoked relative & \\
to manufactured cigarette of same & \\
tar level & \\
Dropped one tar group & \\
Dropped two or more tar groups & $-0.004(0.040)$ \\
\hline $\mathrm{N}=308$ & $0.004(0.051)$ \\
\hline p $<0.05$ &
\end{tabular}

and respiratory symptoms and pulmonary function is that there is usually no information on respiratory symptoms and pulmonary function of smokers at the time they change from high to low tar cigarettes. According to the recent OPCS survey, ${ }^{14}$ smokers who had changed their brand from one tar group to another had done so mainly in the 1970 s. In the $\frac{T}{D}$ HDPP, smokers who had changed tar groups had been smoking their current cigarette brand for an average of seven years, that is, also since the mid 1970s. The HDPP data showed that those men smoked cigarettes with high tar and nicotine yields in 1971. If high tar cigarettes were particularly deleterious, men who smoked them might have had more phlegm and poorer lung function before they changed tar groups. A comparison between men changing and not changing कs to a cigarette in a low tar group would then be biased. $\overrightarrow{0}$ However, there was no difference in mean FEV between these types of smoker in the HDPP. There $\vec{\omega}$ was a tendency for the prevalence of morning phlegm $\vec{\infty}$ at the start of the study to increase from $28 \%$ among $\stackrel{\rho}{3}$ men who always smoked a cigarette in the same tar group to $37 \%$ among those who subsequently i dropped two or more tar groups. However, as the proportion of smokers with phlegm in 1971 who $\vec{\circ}$ changed to a lower tar cigarette $(79 \%)$ was similar th the proportion of smokers without phlegm who subsequently changed down $(75 \%)$, it is unlikely that $ᄃ$ respiratory symptoms influenced the smoker decision to change to a lower tar cigarette.

If there was a direct relationship between reductio in tar yield and reduction of respiratory symptoms and loss of ventilatory capacity, a dose-response relationship in the form of consistent trends from men keeping to a cigarette of the same tar level, through men dropping one tar group, to men dropping two tar levels might be expected in smaller mean drops in $\mathrm{FEV}_{1}$ and reduced prevalence of morning phlegm production. Although men dropping one tar level were more likely to cease phlegm production than those keeping to the same tar level, there was little evidence that those dropping two levels could have benefitted more than those dropping one level, even accounting for sampling error. Results for drop in $\mathrm{FEV}_{1}$ tended to suggest the same.

It was originally expected that if there had been a trend in cessation of phlegm among smokers, it would have been accompanied by a similar trend for a reduction in the development of phlegm among those smokers who did not have phlegm at the start of the HDPP. In fact there was a trend for the proportion of men developing phlegm for the first time to increase from smokers who always smoked a cigarette in the same tar group through to those who subsequently dropped two or more tar groups. In retrospect, it is likely that cessation of phlegm production is a more 
sensitive marker of the benefits of a reduction in the tar yield of cigarettes than a reduction in the development of symptoms for the first time. The latter might be influenced more by the number of cigarettes smoked and the number of years of smoking than by a relatively recent reduction in the tar yield of the cigarettes smoked. The production of the tar yield and number of cigarettes smoked by men in 1971 increased from $343 \mathrm{mg}$ tar per day for men who subsequently did not change down to 398 and $425 \mathrm{mg}$ tar per day for smokers who dropped one and two tar levels respectively. Therefore it might be expected that more smokers who dropped two tar groups might develop symptoms de novo than smokers in the other two groups because of differences in the groups' pre 1971 smoking histories.

It was only the smokers who dropped two or more tar groups who needed to compensate for a large reduction in the nicotine yield of their cigarettes by inhaling more deeply or puffing more frequently. If this were the case, they might have taken in similar amounts of tar as the smokers who kept to cigarettes in the same tar group, which would explain the lack of a dose-response relationship between falling tar and morning phlegm cessation and fall in FEV . The current urinary excretion of nicotine metabolites in the group who dropped two or more tar groups was similar to that in the non-changers. Because of the lack of a suitable way of measuring tar intake the relationship between tar intake and the urinary excretion of nicotine metabolites has not been studied. However, both nicotine and tar occur in the particulate phase of tobacco smoke, and it is highly likely that the excretion of nicotine metabolites is correlated with the amount of tar inhaled. ${ }^{19}$ The ratio of the tar yields to the nicotine yields of the cigarettes smoked by the three groups of smokers in 1984 were similar, 12: 1. Therefore if the excretion of nicotine metabolites of the smokers who changed down two tar groups was similar to that of non-changers, and they smoked cigarettes with similar tar: nicotine yields, it is highly likely that in 1984 they were inhaling similar amounts of tar. Although there is no information about urinary excretion of nicotine metabolites at the start of the study, this observation suggests that the men who dropped two or more tar groups did compensate for the reduction in the nicotine yield of their cigarettes by changing their pattern of smoking. It is well established that smokers do change their pattern of smoking when presented with lower tar, lower nicotine cigarettes (see ${ }^{19}$ for references).

Although smokers who changed tar groups did not differ in morning phlegm production and $\mathrm{FEV}_{1}$ before they changed, a comparison with non-changers could still be biased if the effects of smoking the higher tar cigarettes were long-term. Only a controlled trial in which "middle" tar cigarette smokers, who are unwilling to stop smoking, are allocated at random to smoke a cigarette of the same or a lower tar group will provide definitive evidence of the potential benefit of changing tar groups on respiratory symptoms and lung function. ${ }^{19}$ Because of the lack of a dose-response relationship between the reduction in the tar yield of the cigarettes smoked by the men in the three groups and reduction in morning phlegm and fall in $\mathrm{FEV}_{1}$, and the strong suggestion that this lack of a dose-response relationship was due to men in the group who changed two or more tar levels compensating for the reduced nicotine yield of their cigarette, it is essential that any such trial shall include a nicotine enhanced low tar cigarette and examine compensation phenomena. Moreover, participants in the HDPP were in their forties when they were enrolled into the study, and it would be preferable if any randomised controlled trial involved smokers who switched brands earlier in their smoking careers when respiratory symptoms and fall in $\mathrm{FEV}_{1}$ are more likely to be reversible or halted.

We thank Professor W W Holland for advice and encouragement to do the study, $\mathrm{Dr} \mathrm{R} F$ Heller, assistant director HDPP, and the factory medical officers for helping us to set up the survey, and Mrs Yvonne Smith and Mrs Linda Clarke for word processing the manuscript. The study was funded by the Tobacco Products Research Trust.

\section{References}

${ }^{1}$ Ferris BG, Chen H, Puleo S, Murphy RLH. Chronic non-specific respiratory disease in Berlin, New Hampshire, 1967 to 1973 . A further follow-up study. Am Rev Respir Dis 1976; 113: 475-85.

2 Comstock GW, Brownlow WJ, Stone RW, Sartwell PE. Cigarette smoking and changes in respiratory findings. Arch Environ Health 1970; 20: 50-7.

${ }^{3}$ Freedman S, Fletcher CM. Changes of smoking habits and cough in men smoking cigarettes with $30 \%$ NSM tobacco substitute. $\mathrm{Br}$ Med J 1976; 1: 1427-30.

${ }^{4}$ Fletcher C, Peto R, Tinker C, Speizer FE. The natural history of chronic bronchitis and emphysema. An eight-year study of early chronic obstructive lung disease in working men in London. New York: Oxford University Press; 1976.

${ }^{5}$ Dean G, Lee PN, Todd GF, Wicken AJ, Sparks DN. Factors related to respiratory and cardiovascular symptoms in the United Kingdom. $J$ Epidemiol Community Health 1978; 32: 86-96.

${ }^{6}$ Schenker MB, Samet JM, Speizer FE. Effect of cigarette tar content and smoking habits on respiratory symptoms in women. Am Rev Respir Dis 1982; 125: 684-90.

${ }_{8}^{7}$ Rimington J. Phlegm and filters. Br Med J 1972; 2: 262-4.

${ }^{8}$ Hawthorne VM, Fry JS. Smoking and health: the association between smoking behaviour, total mortality, and cardio-respiratory disease in west central Scotland. $J$ Epidemiol Community Health 1978; 32: 260-6. 
${ }^{9}$ Higenbottam T, Shipley MJ, Clark TJH, Rose G. Lung function and symptoms of cigarette smokers related to tar yield and number of cigarettes smoked. Lancet 1980; 1: 409-12.

${ }^{10}$ Sparrow D, Stefos T, Bosse R, Weiss S. The relationship of tar content to decline in pulmonary function in cigarette smokers. Am Rev Respir Dis 1983; 127: 56-8.

11 Beck GJ, Doyle CA, Schachter EN. Smoking and lung function. Am Rev Respir Dis 1981; 123: 149-55.

12 Peto R, Speizer FE, Cochrane AL, Moore F, Fletcher CM, Tinker CM, Higgins ITT, Gray RG, Richards SM, Gilliland J, Norman-Smith B. The relevance in adults of air-flow obstruction, but not of mucus hypersecretion, to mortality from chronic lung disease. Am Rev Respir Dis 1983; 128: 491-500.

13 Tashkin DP, Clark VA, Coulson AH, Bourque LB, Simmons M, Reems C, Detels R, Rokaw S. Comparison of lung function in young non-smokers and smokers before and after initiation of the smoking habit: a prospective study. Am Rev Respir Dis 1983; 128: 12-6.
14 Marsh A, Matheson J. Smoking attitudes and behaviour. OPCS Social Survey Division, HMSO, 1983.

15 Rose G, Heller RF, Pedoe HT, Christie DGS. Heart Disease Prevention Project: a randomised controlled trial in industry. $\mathrm{Br}$ Med $J$ 1980; 1: 747-51.

${ }^{16}$ Peach H, Ellard GA, Jenner PJ, Morris RW. A simple, inexpensive urine test of smoking. Thorax 1985; 40: 351-7.

${ }^{17}$ Ellard GA, Gammon PT, Helmy HS, Rees RJW. Urine test to monitor the self-administration of dapsone by leprosy patients. Am J Trop Med Hyg 1974; 23: 464-70.

${ }^{18}$ Surgeon General. The health consequences of smoking. Chronic obstructive lung disease. Maryland: US Department of Health and Human Services, 1984.

${ }^{19}$ Peach H, Ellard GA, Hayward D, Shah D. A randomised controlled trial of the effects of a low versus a middle tar cigarette on respiratory symptoms-a feasibility study. In: A major international health hazard (eds DG Zaridze, $\mathbf{R}$ Peto). Lyon: IARC, in press. 